\title{
Effect of different drying methods on the nutritional and physicochemical properties of unpeeled banana flour
}

\author{
Sang Q. Tran ${ }^{1}$, Tuyen C. Kha ${ }^{1}$, \& Khanitta Ruttarattanamongkol ${ }^{2 *}$ \\ ${ }^{1}$ Faculty of Food Science and Technology, Nong Lam University, Ho Chi Minh City, Vietnam \\ ${ }^{2}$ Faculty of Agriculture, Nature Resources and Environment, Naresuan University, Phitsanulok, Thailand
}

\author{
ARTICLE INFO \\ Research Paper \\ Received: April 19, 2019 \\ Revised: June 19, 2019 \\ Accepted: June 28, 2019 \\ Keywords \\ Banana flour \\ Drying method \\ Physicochemical properties

\section{* Corresponding author} \\ Khanitta Ruttarattanamongkol \\ Email: khanittar@nu.ac.th
}

\begin{abstract}
This work was conducted to evaluate the effect of drying methods on the nutritional values and physicochemical properties of unpeeled banana flour. Proximate, amylose content, phenolic compound, resistant starch, total dietary fibre, functional properties, pasting properties, and thermal properties of dried banana flour samples were evaluated. Three different drying methods of whole banana with the intact peel were studied including 1) hot-air unpeeled flour (HAU) (dried at $60^{\circ} \mathrm{C}$ for $2 \mathrm{~h}$ in hot-air chamber), 2) microwave-vacuum unpeeled flour (MVU) (36,000 $\mathrm{W}$ under vacuum $-600 \mathrm{mmHg}$ for $15 \mathrm{~min}$ in a pilot microwavevacuum dryer), and 3) infrared unpeeled flour (IRU) (600 W for 15 min in infrared channel dryer). The HAU and MVU showed the highest yield. Drying methods did not affect the compositions of the flour but significantly affected the total dietary fibre, resistant starch, amylose content and phenolic compound of the flour. Among samples, HAU contained the highest nutritional values with outstanding functional properties, and pasting properties. The unpeeled banana flour can be utilized in various food products such as noodle, bakeries, snack or used as functional ingredients for nutritional purposes.
\end{abstract}

Cited as: Tran, S. Q., Kha, T. C., \& Ruttarattanamongkol, K. (2019). Effect of different drying methods on the nutritional and physicochemical properties of unpeeled banana flour. The Journal of Agriculture and Development 18(3), 64-73.

\section{Introduction}

Banana is used popularly among all classes of people due to its widely available, cheap with great nutritive and medicinal values. In recent times, interest in using banana at the green stage as a food ingredient has been aroused because of its high carbohydrate content, especially resistant starch which is considered as a functional food (Mastro et al., 2007; Mohapatra et al., 2010). The banana peel has been reported to contain a high amount of dietary fibre, minerals, vitamins and polyphenolic compounds (Anjum et al., 2014). Consequently, banana peel is a great potential material that could be considered and developed for further application. However, banana production has been excessive, causing a large amount of bananas to be reduced in price or wasted due to the lack of well-organized and proficient preservation techniques (Maskan, 2000); and banana peel is mostly discarded to be used as fertilizer in landfills, animal feed or waste. Therefore, preservation technique should be investigated to extend the shelf-life and the utilization of banana peel is necessary to maximize the benefit of banana and increase the productivity of banana production.

Hot-air drying is a conventional drying method which has low energy efficiency and a long drying time (Adu \& Otten, 1996; Feng \& Tang, 1998). For this reason, it may cause substantially undesirable impact on quality of dried products (Lin et al., 1998; Drouzas et al., 1999). Microwavevacuum and infrared heating are characterized by rapid and uniform heating which could be the alternative for hot-air drying.

In this study, hot-air drying chamber, 
microwave-vacuum chamber and infrared channel were investigated as preservation techniques for prolonging the shelf-life of unpeeled banana by lowering its moisture content. Proximate, total dietary fibre, resistant starch, amylose content and phenolic compound were analyzed to figure out the effect of the three different drying methods on nutritional value of banana flour. Functional properties, thermal properties, pasting properties and colour were also evaluated among the three drying methods to understand the physical properties of banana flour.

\section{Materials and Methods}

\subsection{Banana flour processing}

The first ripeness stage of banana Pisang Awak Musa obtained from Phitsanulok Province, Thailand was chosen based on the standard ripeness chart (Kader, 1996) for producing banana flour. The preparation of banana flour was made by using the method of Arisa et al. (2013) with a slight modification. Individual banana fruits with intact peel were obtained from banana bunches by cutting and washing. After that, they were sliced into $2 \mathrm{~mm}$ thickness using a kitchen slicer and immediately soaked into sodium metabisulfite $0.1 \%$ for $5 \mathrm{~min}$. Then, they were separated into 3 parts for being dried using 3 different drying methods including $60^{\circ} \mathrm{C}$ for $2 \mathrm{~h}$ in hot-air chamber (HAU), $36,000 \mathrm{~W}$ under vacuum $-600 \mathrm{mmHg}$ for $15 \mathrm{~min}$ in a pilot microwave-vacuum dryer (MVU), and 600 $\mathrm{W}$ for $15 \mathrm{~min}$ in infrared channel dryer (IRU). The dried banana slices were ground into powder using a grinder DXFill model DXM 2000 and then screened through a 60 mesh sieve. The banana flour was packed in an aluminium pack and stored at $-18^{0} \mathrm{C}$.

\subsection{Analysis}

\subsubsection{Production yield}

Production yield was determined by dividing the weight of the obtained banana flour (dry basis) by the weight of the fresh banana fruit, and then multiply by 100 .

\subsubsection{Water activity}

Water activity of samples was measured using Lab swift water activity meter.

\subsubsection{Proximate}

Proximate in terms of moisture, protein, crude fat and ash was analysed by the method described in AOAC (1990).

\subsubsection{Amylose content}

The amylose content measurement was done according to the method of Almeida et al. (2010) with a slight modification. Briefly, a total of 100 mg sample was homogenized with $1 \mathrm{~mL}$ of $95 \%$ ethanol and $9 \mathrm{~mL}$ of $1 \mathrm{M} \mathrm{NaOH}$. The sample was heated for $10 \mathrm{~min}$ in a boiling-water bath to gelatinize the starch. After cooling, it was transferred into a volumetric flask and the volume was made up to $100 \mathrm{~mL}$ with water. Then $1 \mathrm{~mL}$ of $1 \mathrm{M}$ acetic acid and $2 \mathrm{~mL}$ of iodine solution $(0.2 \% \mathrm{I} 2$, $2 \% \mathrm{KI}$ ) was added to a $5 \mathrm{~mL}$ aliquot. The solution was made up to $100 \mathrm{~mL}$ with water and allowed to stand for $10 \mathrm{~min}$. Spectrophotometric quantification was performed at $620 \mathrm{~nm}$, with a UV-Vis spectrophotometer Shanghai Metash Instrument. The apparent amylose content was calculated using an equation obtained from the standard curve using purified amylose and amylopectin extracted from potato tubers.

\subsubsection{Phenolic compound}

Phenolic compound was measured using the method of Yang et al. (2014) with a slight modification. Briefly, the sample $(5 \mathrm{~g})$ was extracted twice with $50 \mathrm{~mL}$ of $80 \%$ (v/v) aqueous ethanol for $30 \mathrm{~min}$ at ambient temperature and centrifuged at $6000 \mathrm{r} / \mathrm{min}$ for $15 \mathrm{~min}$ at $20^{\circ} \mathrm{C}$. The supernatants were collected, combined, and then evaporated under vacuum -300 mbar at $40^{\circ} \mathrm{C}$ in Evaporator apparatus (Büchi Rotavapor R-114; Büchi Waterbath B-480, Büchi Vacuum-System B-169) to dry and reconstituted in $100 \mathrm{~mL}$ of distilled water. Phenolic compound was measured using Folin-Ciocalteu method.

\subsubsection{Resistant starch}

Resistant starch was determined by using the method of Megazyme International Ireland. Briefly, the sample was incubated in $4.0 \mathrm{~mL}$ of pancreatic $\alpha$-amylase solution at $37^{\circ} \mathrm{C}$ with continuous shaking for 16 hours. Ethanol $(99 \% \mathrm{v} / \mathrm{v})$ of $4 \mathrm{~mL}$ was added and vigorously stirred on the vortex mixer. The tubes were centrifuged at 3,000 
rpm for $10 \mathrm{~min}$ (non-capped). The supernatants were carefully decanted and the pellets were resuspended in $2 \mathrm{~mL}$ of $50 \%$ ethanol and vigorously stirred on the vortex mixer. Accurately 6 $\mathrm{mL}$ of $50 \%$ IMS was further added and the solution was centrifuged again at $3000 \mathrm{rpm}$ for $10 \mathrm{~min}$ using centrifuge universal 320 . The supernatants were decanted. These suspension and centrifugation steps were repeated once more. The pellets were re-suspended in $2 \mathrm{~mL}$ of $2 \mathrm{M} \mathrm{KOH}$ and stirred for approximate $20 \mathrm{~min}$ in an ice/water bath. Accurately $8 \mathrm{~mL}$ of $1.2 \mathrm{M}$ sodium acetate buffer ( $\mathrm{pH} 3.8$ ) was added. The mixture was incubated in $0.1 \mathrm{~mL}$ of $\mathrm{AMG}$ at $50^{\circ} \mathrm{C}$ for $30 \mathrm{~min}$. To measure resistant starch, accurately $0.1 \mathrm{~mL}$ aliquots (in duplicate) was mixed with $3.0 \mathrm{~mL}$ of GOPOD reagent, the mixture was incubated at $50^{\circ} \mathrm{C}$ for $20 \mathrm{~min}$. The absorbance of the mixture was measured at $510 \mathrm{~nm}$ against the reagent blank.

\subsubsection{Total dietary fibre}

Total dietary fibre was determined by using the method of Megazyme International Ireland. Briefly, duplicate of samples were mixed with 10ml MES-TRIS solution using magnetic stirring bar. After that, the mixture was incubated in 50 $\mu \mathrm{L}$ thermostable $\alpha$-amylase solution at $98-100^{\circ} \mathrm{C}$ for $30 \mathrm{~min}$ and $100 \mu \mathrm{L}$ protease solution at $60^{\circ} \mathrm{C}$ for 30 min successively with continuous agitation. Accurately $5 \mathrm{~mL}$ of $0.561 \mathrm{~N} \mathrm{HCl}$ was dispersed into the mixture and the $\mathrm{pH}$ was adjusted with additional $5 \% \mathrm{NaOH}$ solution. The mixture was incubated in $200 \mu \mathrm{L}$ amyloglucosidase solution at $60^{\circ} \mathrm{C}$ for $30 \mathrm{~min}$ with continuous agitation. The insoluble fibre in the mixture was filtrated using filter paper Whatman number 4 . The soluble fibre in the filtrate was precipitated by incubating in $\mathrm{EtOH} 95 \%$ at $60^{\circ} \mathrm{C}$ for $60 \mathrm{~min}$. The soluble fibre was filtrated using filter paper Whatman number 4. Each replicate of the insoluble and soluble fibre filter paper was measured for protein and ash. Dietary fibre is the sum of insoluble and soluble fibre.

\subsubsection{Functional properties}

The water absorption index (WAI), water solubility index (WSI) and swelling power index (SPI) were determined according to a reported method of Tong et al. (2015) with a slight modification. Briefly, about $0.1 \mathrm{~g}$ of sample was dis- persed in $20 \mathrm{~mL}$ deionized water and agitated at $25^{\circ} \mathrm{C}$ and $100^{\circ} \mathrm{C}$ for 30 min using shaking water bath JSR model JSSB-30T, respectively. After centrifuging the dispersion at $15,000 \mathrm{~g}$ for 30 min using a Hermle Z206A centrifuge, the supernatant was dried in a hot-air oven SNOL at $105^{\circ} \mathrm{C}$ until a constant weight was obtained. WAI, WSI and SPI were calculated by the following formulas:

Water absorption index $=$

$$
\frac{\text { wet sediment weight }}{\text { dry sample weight }}
$$

Water solubility index $(\%)=$

$$
\frac{\text { dried supernatant weight }}{\text { dry sample weight }} \times 100
$$

Swelling power index $=$

$$
\frac{\text { wet sediment weight }}{\text { dry sample weight } \mathrm{x}(1-\mathrm{WSI})}
$$

The oil absorption index (OAI) was determined based on the protocol developed by Kraithong et al. (2018) with a slight modification. The sample of $1 \mathrm{~g}$ was mixed with $10 \mathrm{~mL}$ of soybean oil bought from Lotus supermarket. The mixture was centrifuged at $4000 \mathrm{rpm}$ for $20 \mathrm{~min}$ using a Hermle Z206A centrifuge. After that, the supernatant was decanted while the residue was weighed. The calculation of OAI was as follows:

$$
\begin{aligned}
& \text { Oil absorption index }\left(\frac{\mathrm{g}}{\mathrm{g}}\right)= \\
& \frac{\text { weight of residues }(\mathrm{g}) \text {-weight of sample }(\mathrm{g})}{\text { weight of dry sample }(\mathrm{g})}
\end{aligned}
$$

\subsubsection{Thermal properties}

Thermal properties in terms of onset temperature, peak temperature, enset temperature and enthalpy were measured using a Mettler Differential Scanning Calorimetry (DSC). The method was followed a procedure of Nimsung et al. (2007). Approximately $5 \mathrm{mg}$ of the sample (dry basis) was weighed directly in a tared stainless pan at temperature of $20^{\circ} \mathrm{C}$ and distilled water was added to get the starch:water ratio of 1:2 (5 mg:10 $\mu \mathrm{L}$ ). The pan containing the sample was hermetically sealed and allowed to equilibrate for 1 hour at room temperature to complete starch hydration before the analysis. After that, the pan was placed in the DSC and heated from 10 to $130^{\circ} \mathrm{C}$ at the rate of $10^{\circ} \mathrm{C} / \mathrm{min}$. An empty pan was used as a reference. The onset $\left(\mathrm{T}_{\mathrm{o}}\right)$, peak $\left(T_{p}\right)$, completion temperature $\left(T_{c}\right)$, and energy of enthalpy $(\Delta \mathrm{H})$ were recorded and computed 
using computer software supplied with the instrument.

\subsubsection{Pasting properties}

The pasting properties in terms of peak viscosity, hot paste viscosity, breakdown, cold paste viscosity, set back, peak time and pasting temperature were determined using a Rapid Visco Analyzer 4500 (Newport Scientific). The method was followed procedure of Nimsung et al. (2007) with a slight modification. The sample of $3 \mathrm{~g}$ (dry basis) was weighed into a disposable aluminium RVA canister, and distilled water was added to obtain a total sample weight of $28 \mathrm{~g}$. The sample was held at $50^{\circ} \mathrm{C}$ for $1 \mathrm{~min}$ and heated to $95^{\circ} \mathrm{C}$ for $4 \mathrm{~min}$ and held at $95^{\circ} \mathrm{C}$ for $2 \mathrm{~min}$, and then cooled from $95^{\circ} \mathrm{C}$ to $50^{\circ} \mathrm{C}$ and held at $50^{\circ} \mathrm{C}$ for 9 $\mathrm{min}$. The RVA parameters including the peak viscosity, hot paste viscosity, breakdown, cold paste viscosity, setback, and pasting temperature were all recorded. All measurements were performed in duplicates.

\subsubsection{Statistical analysis}

An analysis of variance (ANOVA) was performed. The data were expressed as the mean \pm SD and analysed by SPSS (version 19 for windows, SPSS Inc., Chicago, IL, USA) using Duncan's Multiple-Range Test at a significant level of $P<0.05$.

\section{Results and Discussion}

\subsection{Production yield and water activity}

Production yield obtained from 3 drying methods of peeled and unpeeled banana flour is presented in Table 1. There was a small difference in production yield among the drying methods except for MVU and HAU which show higher production yield ( $25.73 \%$ and $25.5 \%$, respectively) than that of IRU. These results were similar to the production yield of green banana flour obtained from 4 types of banana reported by Yani et al. (2013) (Janten $35-36 \%$, Kepok Manado 19 - 20\%, Muli $16-17 \%$ and Raja Nangka 20 $21 \%$ ). Yani et al. (2013) stated that the difference of production yield might be due to the maturity stages of bananas which is related to the starch content and properties. Microwave-vacuum drying and hot-air drying could be considered to ap- ply for producing unpeeled banana flour regarding the economic benefit and production yield.

In general, the water activity of banana flour dried by the 3 drying methods was lower than 0.6 which is the safe level for preserving the product. MVU exhibited the lowest water activity $(0.326)$ and there were not significant differences in the water activity between HAU (0.482) and IRU (0.469). As a result, the most effective drying method for reducing water activity was microwave-vacuum.

Table 1. Production yield (\% dry basis) and water activity of banana flour

\begin{tabular}{ccc}
\hline Samples & $\begin{array}{c}\text { Production } \\
\text { yield }\end{array}$ & Water activity \\
\hline HAU & 25.50 & $0.482 \pm 0.060^{\mathrm{a}}$ \\
MVU & 25.73 & $0.326 \pm 0.017^{\mathrm{b}}$ \\
IRU & 22.68 & $0.469 \pm 0.001^{\mathrm{a}}$ \\
\hline
\end{tabular}

Values are shown as mean $\pm \mathrm{SD} ;{ }^{\mathrm{a}-\mathrm{b}}$ Different letters in the same column are significantly different $(P<0.05)$; HAU: Hot-air unpeeled; MVU: Microwave-vacuum unpeeled; IRU: Infrared unpeeled.

\subsection{Proximate analysis}

Proximate of banana flour including moisture content, protein, crude fat, ash and carbohydrate is presented in Table 2. The moisture content was highest in IRU (12.14\%) and lowest in MVU $(5.38 \%)$. It might be due to the high processing temperature and shallow depth effect of infrared which caused the cake hardening phenomenon which prevents moisture from diffusion and evaporation; and in microwave vacuum drying, the heat created by ionic polarization or dipole rotation transfer within the food by conduction or convection so that the inner and outer parts of food receive the same energy or the moisture content is removed thoroughly.

Protein ranged from $2.80 \%$ in IRU to $3.03 \%$ in MVU and there were not significant differences in protein content among different drying methods. The results were close to the range of $2.55-3.41 \%$ in banana flours reported by Yani et al., (2013), $2.50-3.0 \%$ reported by Mota et al. (2000) and $1.88-4.47 \%$ reported by Nimsung et al. (2007). The variance of protein content in banana flour was caused by some factors such as weather, soil nutrient and varieties (Yani et al., 2013) and matuirty stage (Emaga et al., 2007).

The range of $0.23 \%$ in IRU and $0.26 \%$ in MVU for crude fat were in agreement with Liao \& Hung 
Table 2. Proximate of banana flour (\% dry basis)

\begin{tabular}{cccccc}
\hline Method & Moisture & Protein $^{\mathrm{ns}}$ & Crude fat $^{\mathrm{ns}}$ & Ash $^{\mathrm{ns}}$ & Carbohydrate $^{\mathrm{ns}}$ \\
\hline HAU & $9.50 \pm 0.20^{\mathrm{b}}$ & $2.84 \pm 0.18$ & $0.24 \pm 0.02$ & $1.94 \pm 0.16$ & $94.98 \pm 0.33$ \\
MVU & $5.38 \pm 0.27^{\mathrm{c}}$ & $3.03 \pm 0.33$ & $0.26 \pm 0.01$ & $1.68 \pm 0.35$ & $95.04 \pm 0.07$ \\
IRU & $12.14 \pm 0.13^{\mathrm{a}}$ & $2.80 \pm 0.11$ & $0.23 \pm 0.02$ & $1.52 \pm 0.16$ & $95.45 \pm 0.23$ \\
\hline
\end{tabular}

Values are shown as mean $\pm \mathrm{SD} ;{ }^{\mathrm{a}-\mathrm{c}}$ Different letters in the same column are significantly different $(P<0.05)$;

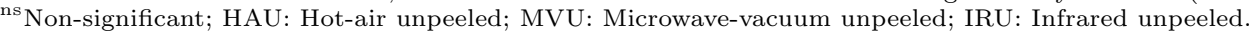

(2015) and Nimsung et al. (2007) who found that the fat content of banana flour was $0.25 \%$ and $1.56-4.88 \%$, respectively. The three drying methods did not have an effect on the fat content of banana flour.

The ash was in the range of $1.52 \%$ in IRU and $1.94 \%$ in HAU. The results also showed that there were not significant differences among the three drying methods $(P>0.05)$. These results were lower than the range of $2.24-3.03 \%$ and $2.6-$ $3.5 \%$, which were reported by Yani et al. (2013) and Mota et al. (2000), respectively. The differences in the ash content might be due to the soil, varieties and planting weather.

Carbohydrate was in the range of $94.98 \%$ in HAU and $95.45 \%$ in IRU and there were not significant differences among 3 drying methods in the carbohydrate content $(P>0.05)$.

\subsection{Total dietary fibre, resistant starch, amy- lose content and phenolic compound}

Total dietary fibre, resistant starch, amylose content and phenolic compound are shown in Table 3. Total dietary fibre ranged from $15.75 \%$ in IRU to $18.38 \%$ in HAU, these values compared reasonably well with the $6.0-15.5 \%$ total fibre reported by Mota et al. (2000).

The highest and lowest amounts of resistant starch were found to be in HAU (60.21\%) and IRU $(34.26 \%)$ respectively. The values were well comparable with those of $48.99 \%$ reported by Menezes et al. (2011) who followed the method of AOAC 2002.02 and $30.3 \%$ reported by Liao \& Hung (2015) whose method was based on the approved method 32 - 40 (AACC, 2000). This difference might be caused by the high temperature and temperature fluctuation in infrared drying that reduced the amount of resistant starch.

Amylose content was found to be highest and lowest in HAU (37.95\%) and IRU (32.17\%) respectively. The difference in amylose content among 3 drying methods might be due to the differences in moisture contents, drying rates, dry- ing temperatures and drying mechanisms. The result shows that there might be a relationship between resistant starch and amylose content since the higher the amylose content, the higher the resistant starch content.

The highest and lowest phenolic compounds were found to be in HAU and IRU respectively. The phenolic content in banana flour was obtained from $20.22 \mathrm{mg}$ GAE/100 $\mathrm{g}$ in IRU to 62.66 mg GAE/100 g in HAU. The phenolic content in HAU and MVU was closely and IRU was pretty lower compared to $50.65 \mathrm{mg}$ GAE/100 g reported by Menezes et al. (2011). The difference might be due to the high and inconsistence of the temperature of different drying systems.

The total dietary fibre, resistant starch and amylose content might be sensitive to high temperature and the temperature fluctuation since they were lowest in the flour produced by infrared drying. The impact of hot-air drying on nutritional value of banana flour was the least comparing to microwave-vacuum drying and infrared drying, even though these 2 drying methods were evaluated to be less undesirable on quality of banana flour. It is appeared that optimization of drying condition of microwave-vacuum and infrared drying should be investigated in order to altarnate the traditional drying method.

\subsection{Functional, thermal and pasting proper- ties}

The functional properties of banana flour including WAI (Water Absorption Index), WSI (Water Solubility Index), SPI (Swelling Power Index) and OAI (Oil Absorption Index) are shown in Table 4. Water Absorption Index (WAI) ranged from $3.15 \mathrm{~g} / \mathrm{g}$ in MVU to $3.59 \mathrm{~g} / \mathrm{g}$ in HAU. WAI exhibits the ability of flour to absorb water molecules (Shafi et al., 2016). It is supported by the hydrophilic groups within the starches, which provide the viscosity, smoothness, and softness in the products (Aprianita et al., 2014). The polar side chains in carbohydrates and proteins could 
Table 3. Total dietary fibre, resistant starch, amylose content and phenolics of banana flour (dry basis)

\begin{tabular}{ccccc}
\hline Samples & $\begin{array}{c}\text { Total dietary fibre } \\
(\%)\end{array}$ & $\begin{array}{c}\text { Resistant starch } \\
(\%)\end{array}$ & $\begin{array}{c}\text { Amylose } \\
(\%)\end{array}$ & $\begin{array}{c}\text { Phenolics } \\
(\mathrm{mg} \text { GAE } / 100 \mathrm{~g})\end{array}$ \\
\hline HAU & $18.38 \pm 0.03^{\mathrm{a}}$ & $60.21 \pm 0.13^{\mathrm{a}}$ & $37.95 \pm 0.98^{\mathrm{a}}$ & $62.66 \pm 0.04^{\mathrm{a}}$ \\
MVU & $17.34 \pm 0.16^{\mathrm{b}}$ & $56.48 \pm 0.90^{\mathrm{b}}$ & $35.07 \pm 1.09^{\mathrm{b}}$ & $57.55 \pm 1.82^{\mathrm{b}}$ \\
IRU & $15.75 \pm 0.12^{\mathrm{c}}$ & $34.26 \pm 0.49^{\mathrm{c}}$ & $32.17 \pm 1.01^{\mathrm{c}}$ & $20.22 \pm 0.34^{\mathrm{c}}$ \\
\hline
\end{tabular}

Values are shown as mean $\pm \mathrm{SD} ;{ }^{\mathrm{a}-\mathrm{c}}$ Different letters in the same column are significantly different $(P<0.05)$;

${ }^{\mathrm{ns}}$ non-significant; HAU: Hot-air unpeeled; MVU: Microwave-vacuum unpeeled; IRU: Infrared unpeeled.

Table 4. The functional properties of banana flour (dry basis)

\begin{tabular}{ccccc}
\hline Samples & WAI $(\mathrm{g} / \mathrm{g})$ & WSI $(\%)$ & SPI $(\mathrm{g} / \mathrm{g})$ & OAI $(\mathrm{g} / \mathrm{g})$ \\
\hline HAU & $3.59 \pm 0.04^{\mathrm{a}}$ & $5.92 \pm 0.15^{\mathrm{a}}$ & $3.82 \pm 0.04^{\mathrm{a}}$ & $2.02 \pm 0.01^{\mathrm{a}}$ \\
MVU & $3.15 \pm 0.02^{\mathrm{c}}$ & $5.13 \pm 0.30^{\mathrm{b}}$ & $3.32 \pm 0.02^{\mathrm{c}}$ & $1.91 \pm 0.04^{\mathrm{b}}$ \\
IRU & $3.43 \pm 0.01^{\mathrm{b}}$ & $5.83 \pm 0.21^{\mathrm{a}}$ & $3.65 \pm 0.02^{\mathrm{b}}$ & $2.02 \pm 0.03^{\mathrm{a}}$ \\
\hline
\end{tabular}

Values are shown as mean $\pm \mathrm{SD} ;{ }^{\mathrm{a}-\mathrm{c}}$ Different letters in the same column are significantly different $(P<0.05)$; HAU: hot-air unpeeled; MVU: microwave-vacuum unpeeled; IRU: Infrared unpeeled; WAI: Water Absorption Index; WSI: Water Solubility Index; SPI: Swelling Power Index; OAI: Oil Absorption Index.

support the hydrogen bonding of the rice flour (Prasad et al., 2012). The water binding capacity is also encouraged by the negative charges of phosphate groups within amylopectin (Wang et al., 2016). The large particle size could reduce the WAI value (Otegbayo et al., 2013). The amylose-lipid and amylose-protein complexes inhibit the polar and charges group from water binding, which reduce the value of WAI (Falade \& Christopher, 2015).

Water Solubility Index (WSI) was obtained in the range of $5.13 \%$ in MVU and $5.92 \%$ in HAU. It is not significantly different between HAU and IRU. The WSI represents the amount of soluble components which disperse in the aqueous solution during cooking (Shafi et al., 2016). The higher the WSI, the higher adhesive and sticky in the products, however, the lower consistent in the food structure (Wang et al., 2016). Junction zone formation by amylose encourages a rigid structure of starch granules, providing low WSI (Chung et al., 2011). The starch-protein and starch-lipid complexes could reduce the value of WSI because the soluble parts are reduced within the starch molecules (Keawpeng \& Meenune, 2012). As a result, the low WSI value is desirable as it indicates the consistent structure of food during cooking (Kraithong et al., 2018).

Swelling Power Index (SPI) was in the range of $3.32 \mathrm{~g} / \mathrm{g}$ in MVU and $3.82 \mathrm{~g} / \mathrm{g}$ in HAU. The starch granules absorb water when it is heated to a critical temperature in the presence of excessive water. The starch granules then swell and a part of starch leaches out into the solution. The extend of swelling and leaching are determined by the strength of chemical bonding within the granules. The strong intermolecular bonds and high amylose content create an extensive network which can reduce the extent of swelling. The complete swelling is reached only after amylose has been leached out of the granules, therefore amylose is believed to restrict swelling. Furthermore, swelling index is also affected by the structure of starch granules. The high open structure of waxy starches allows rapid water penetration, swelling, and solubility. The swelling capacity of the starch granules is restricted by the increase of amylose content which can limit the amount of starch exudates leaching into solution. However, there are other factors affecting the swelling and solubility of starch granules (Bhattacharya et al., 1999).

Oil Absorption Index (OAI) was obtained from $1.91 \mathrm{~g} / \mathrm{g}$ in MVU to $2.02 \mathrm{~g} / \mathrm{g}$ in HAU and IRU. OAI was the highest and not significant different in HAU and IRU. The OAI value exhibits the ability to retain oil in the starch granules (Kraithong et al., 2018). It is supported by the hydrophobic groups within the starch molecules (Tharise et al., 2014). The flour with high OAI value promotes the mouth-feel, palatability, and flavour retention in the products. However, the rancidity is increased due to high value of OAI (Falade \& Christopher, 2015).

The pasting properties including peak viscosity, hot paste viscosity, breakdown, cold paste viscosity, setback, peak time and pasting tem- 
perature are presented in Table 5 . The pasting profile could be related to the molecular characteristics of the starch components such as lipid and amylose. Furthermore, the morphology of the starch granules could affect the starch property (Nimsung et al., 2007). The variations in pasting properties are accounted by the differences in flour composition (Oko \& Ugwu, 2011). The amylose is considered to reduce peak, hot paste, and breakdown viscosities, however, increase the setback, cold paste viscosities, and pasting temperature (Ye et al., 2016). However, the results in this study shows that amylose content had a tendency to increase peak viscosity, hot paste viscosity, breakdown, cold paste and speed up the peak time. The result also demonstrated that resistant starch and total dietary fibre showed the same relationship as amylose content with pasting properties. Protein and lipid also affect the pasting properties. The setback and cold paste viscosities are increased while the peak and breakdown viscosities are reduced by the formations of amylose-protein complex or amylose-lipid complex (Alcazar-Alay \& Meireles, 2015). The protein with hydrophilic groups could increases the peak viscosity of rice flour (Hsu et al., 2015). The pasting properties of the flour are determined by the rigidity of starch granules which affects the granule swelling potential.

Peak viscosity values of HAU, MVU and IRU were 404, 313 and 263 RVU respectively and were significantly different $(P<0.05)$. The peak viscosity presents the water binding ability of the starch granule via hydrogen bonds (Otegbayo et al., 2013). The amylopectin content is responsible for high peak viscosity due to its high water holding capacity (Ye et al., 2016). Furthermore, small particle size with large surface area also increases the viscosity (Prasad et al., 2012). Higher peak viscosity is caused by higher breakdown because less heat and shear stress resistance during cooking (Hsu et al., 2015). Hot paste viscosity values of HAU, MVU and IRU were 267, 243 and 222 RVU, respectively. The Hot paste viscosity presents for the minimum viscosity at constant temperature. Breakdown viscosity of HAU, MVU and IRU were 137, 70, and 40, respectively. The high breakdown viscosity is resulted of the composition such as protein, lipid and amylose content. Cold paste viscosity of HAU, MVU and IRU were 408,385 , and 363 , respectively. The cold paste viscosity presents for the stability of cooked paste and ability to form gel after cool-

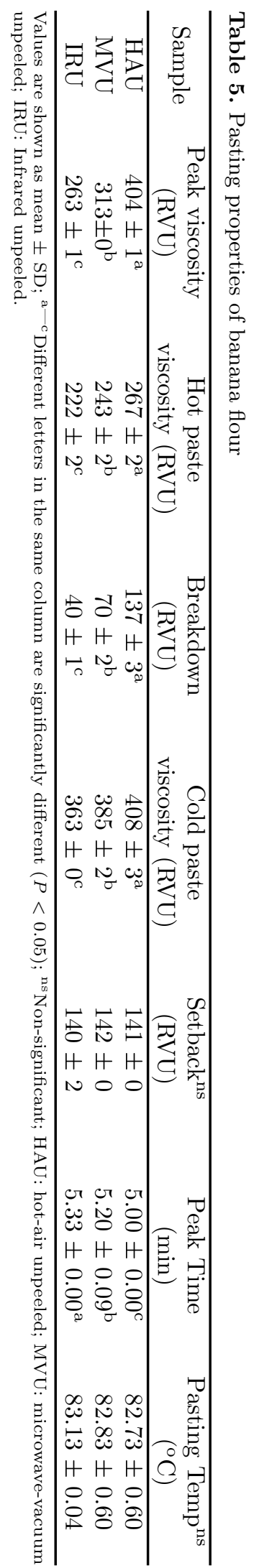


Table 6. Thermal properties of banana flour

\begin{tabular}{ccccc}
\hline Samples & Onset $\left({ }^{\circ} \mathrm{C}\right)$ & Peak $\left({ }^{\circ} \mathrm{C}\right)$ & Endset $\left({ }^{\circ} \mathrm{C}\right)$ & Enthapy $(\mathrm{J} / \mathrm{g})$ \\
\hline HAU & 74.04 & 77.83 & 82.68 & 4.18 \\
MVU & 74.18 & 77.83 & 81.49 & 2.40 \\
IRU & 74.74 & 78.74 & 83.64 & 3.14 \\
\hline
\end{tabular}

HAU: hot-air unpeeled; MVU: microwave-vacuum unpeeled; IRU: Infrared unpeeled.

ing. Setback viscosity of HAU, MVU and IRU were 141, 142 and 140, respectively. The setback viscosities of banana flour were not significantly different $(P>0.05)$ among 3 drying methods. The high setback during cooling represents the high retrogradation which is due to the effect of amylose and amylopectin (Nimsung et al., 2007). The retrogradation process occurs faster in the starch which has higher amylose content (Suwonsichon et al., 2011). The increase in setback value is due to the amylose re-association upon cooling which creates a 3-dimensional gel network (Jamal et al., 2016). The peak time was in the range of $5.00-5.33 \mathrm{~min}$ and the pasting temperature was in the range of $82.73^{\circ} \mathrm{C}-83.13^{\circ} \mathrm{C}$ in $\mathrm{HAU}$ and IRU respectively.

Table 6 shows the thermal properties of banana flour including onset temperature, peak temperature, endset temperature and enthalpy. The overall gelatinization temperature range of banana flours was $74.04-83.64^{\circ} \mathrm{C}$, which was comparable to the range $\left(70.70-86.18^{\circ} \mathrm{C}\right)$ reported by Nimsung et al. (2007) and the range $\left(62.3-86.9^{\circ} \mathrm{C}\right)$ reported by Mota et al. (2000). The mean onset temperature was $74.32^{\circ} \mathrm{C}$, ranging from $74.04^{\circ} \mathrm{C}$ in $\mathrm{HAU}$ to $74.74^{\circ} \mathrm{C}$ in IRU. The peak temperature ranged from $77.83^{\circ} \mathrm{C}$ in $\mathrm{HAU}$ and $\mathrm{MVU}$ to $78.74^{\circ} \mathrm{C}$ in IRU, with the mean of $78.13^{\circ} \mathrm{C}$, while the final temperature showed an average of $82.60^{\circ} \mathrm{C}$, ranging from $81.49^{\circ} \mathrm{C}$ in $\mathrm{MVU}$ to $83.64^{\circ} \mathrm{C}$ in IRU. There was a negative relation between gelatinization and pasting properties in terms of peak viscosity, hot paste viscosity, breakdown and cold paste viscosity. The enset temperature was close to the value of pasting temperature measured by Rapid Visco Analyzer. Gelatinization enthalpy varied from $2.40 \mathrm{~J} / \mathrm{g}$ in MVU to $4.18 \mathrm{~J} / \mathrm{g}$ in $\mathrm{HAU}$, with the mean of $3.24 \mathrm{~J} / \mathrm{g}$, which was much lower than the values of 10.8 $13.3 \mathrm{~J} / \mathrm{g}$ reported by Mota et al. (2000) and 15.16 - $19.62 \mathrm{~J} / \mathrm{g}$ reported by Nimsung et al. (2007).

The differences in gelatinization temperature were accounted by the differences in amylose content, the distribution, size and form of starch granules as well as the internal arrangement of starch fractions within the granules (Singh et al., 2003). As shown in this study, the amylose content, total dietary fibre and resistant starch were negatively related to gelatinization temperature. The enthalpy represents the melting of amylopectin crystallites. The differences in enthalpy appear to be attributed to the differences in bonding forces between the double helices that form amylopectin crystallites, resulting in different alignment of hydrogen bonds within starch molecule (McPherson \& Jane., 1999). The higher values of DSC parameter are encouraged by large amylopectin branches (crystallinity) (Kraithong et al., 2018). According to Alcazar-Alay \& Meireles (2015), high energy is required for disrupting the large crystalline regions of high amylopectin rice flour. Besides, amylose-lipid and amyloseprotein complex formations also can increase the gelatinization temperature due to their structures (Morales-Martínez et al., 2014). In contrast, the gelatinization of flour with high amorphous regions (high amylose) is accomplished easily because of weak hydrogen bonds (Jamal et al., 2016). The small particle size of rice flour advocates low gelatinization temperature because of large surface areas for binding water molecules (Ye et al., 2016).

\section{Conclusion}

Productivity was highest in hot-air drying and microwave vacuum drying. Drying method did not have any significant effects on proximate of unpeeled banana flour. Total dietary fibre, resistant starch, amylose content and phenolic compound of the flour produced by microwavevacuum drying were fairly high, however, these were less than those contained in the flour produced by hot-air drying. Therefore, hot-air drying was still the superior method for preserving those nutritional values. The flour produced by hot-air drying exhibited the highest functional properties such as WAI (3.59 g/g), WSI $(5.92 \%)$, SPI (3.82 $\mathrm{g} / \mathrm{g})$ and OAI $(2.02 \mathrm{~g} / \mathrm{g})$. Pasting properties of 
the flour were also highest for hot-air drying. The gelatinization was highest in infrared drying and the enthalpy was highest in hot-air drying.

\section{References}

Adu, B., \& Otten, L. (1996). Effect of increasing hygroscopicity on the microwave heating of solid foods. Journal of Food Engineering 27, 35-44.

Alcazar-Alay, S. C., \& Meireles, M. A. A. (2015). Physicochemical properties, modifications and applications of starches from different botanical sources. Food Science and Technology 35(2), 215-236.

Almeida, M. R., Alves, R. S., Nascimbem, L. B. L. R., Stephani, R., Poppi, R. J., \& Oliveira, L. F. C. d. (2010). Determination of amylose content in starch using Raman spectroscopy and multivariate calibration analysis. Analytical and Bioanalytical Chemistry 397, 2693-2701.

Anjum, S., Sundaram, S., \& Rai, G. (2014). Nutraceutical application and value addition of banana (Musa paradisica L. Variety, "Bhusawal Keli") peel: A review. International Journal of Pharmacy and Pharmaceutical Sciences 6(10), 81-85.

Aprianita, A., Vasiljevic, T., Bannikova, A., \& Kasapis, S. (2014). Physicochemical properties of flours and starches derived from traditional Indonesian tubers and roots. Food Science and Technology 51(2), 36693679 .

Arisa, N. U., Adelekan, A. O., Alamu, A. E., \& Ogunfowora, E. J. (2013). The effect of pretreatment of plantain (Musa Parasidiaca) flour on the pasting and sensory characteristics of biscuit. International Journal of Food and Nutrition Science 2(1), 10-24.

Bhattacharya, M., Zee, S. Y., \& Corke, H. (1999). Physicochemical properties related to quality of rice noodles. Cereal Chemistry 76(6), 861-867.

Chung, H. J., Liu, Q., Lee, L., \& Wei, D. (2011). Relationship between the structure, physicochemical properties and in vitro digestibility of rice starches with different amylose contents. Food Hydrocolloid 25, 968-975.

Drouzas, A. E., Tsami, E., \& Aravacos, G. D. (1999). Microwave-vacuum drying of model fruit gels. Journal of Food Engineering 39, 117-122.

Emaga, T. H., Andrianaivo, R. H., Wathelet, B., Tchango, J. T., \& Paquot, M. (2007). Effects of the stage of maturation and varieties on the chemical composition of banana and plantain peels. Food Chemistry 103, 590-600.

Falade, K. O., \& Christopher, A. S. (2015). Physical, functional, pasting and thermal properties of flours and starches of six Nigerian rice cultivars. Food Hydrocolloid 44, 478-490.

Feng, H., \& Tang, J. (1998). Microwave finish drying of diced apples in a spouted bed. Journal of Food Science 63(4), 679-683.
Hsu, R. J. C., Lu, S., Chang, Y. H., \& Chiang, W. (2015). Effects of added water and retrogradation on starch digestibility of cooked rice flours with different amylose content. Journal of Cereal Science 61, 1-7.

Jamal, S., Qazi, I. M., \& Ahmed, I. (2016). Comparative studies on flour proximate compositions and functional properties of selected Pakistani rice varieties. Proceedings of the Pakistan Academy of Sciences 53(1), 47-56.

Kader, A. A. (1996). Banana: Recommendations for maintaining postharvest quality. Perishables Handling \#88. Retrieved March 6, 2019, from http://postharvest.ucdavis.edu/files/259413.pdf.

Keawpeng, I., \& Meenune, M. (2012). Physicochemical properties of organic and inorganic Phatthalung Sungyod rice. Food Research International 19(3), 857861.

Kraithong, S., Lee, S., \& Rawdkuen, S. (2018). Physicochemical and functional properties of Thai organic rice flour. Journal of Cereal Science 79, 259-266.

Liao, H. J., \& Hung, C. C. (2015). Chemical composition and in vitro starch digestibility of green banana (cv. Giant Cavendish) flour and its derived autoclaved/debranched powder. Food Science and Technology 64, 639-644.

Lin, T. M., Durance, T. D., \& Scaman, C. H. (1998). Characterization of vacuum microwave air and freeze dried carrot slices. Food Research International 31(2), 111-117.

Maskan, M. (2000). Microwave/air and microwave finish drying of banana. Journal of Food Engineering 44, 7178.

Mastro, N. L., Taipina, M. S., Cohen, V. H., \& Rodas, M. A. B. (2007). Avaliação critica da polpa de banana (Musa spp) verde. Revista Higiene Alimentar 21, 3945 .

McPherson, A. E., \& Jane, J. (1999). Comparison of waxy potato with other root and tuber starches. Carbohydrate Polymers 40, 57-70.

Menezes, E. W., Tadini, C. C., Tribess, T. B., Zuleta, A., Binaghi, J., Pak, N., Vera, G., Dan, M. C., Bertolini, A. C., Cordenunsi, B. R., \& Lajolo, F. M. (2011). Chemical composition and nutritional value of unripe banana flour (Musa acuminata, var. Nanicão). Plant Foods for Human Nutrition 66(3), 231-237.

Mohapatra, D., Mishra, S., \& Sutar, N. (2010). Banana and its by product utilisation. Journal of Scientific and Industrial Research 69(5), 323-329.

Morales-Martínez, L. E., Bello-Perez, L. A., SanchezRivera, M. M., Ventura-Zapata, E., \& JimenezAparicio, A. R. (2014). Morphometric, physicochemical, thermal, and rheological properties of rice (Oryza sativa L.) cultivars indica japonica. Food and Nutrition Science 5, 271-279.

Mota, R. V. d., Lajolo, F. M., Ciacco, C., \& Cordenunsi, B. R. (2000). Composition and functional properties of banana flour from different varieties. Starch 52(23), 63-68. 
Nimsung, P., Thongngam, M., \& Naivikul, O. (2007). Compositions, morphological and thermal properties of green banana flour and starch. Kasetsart Journal (Natural Science) 41, 324-330.

Oko, A. O., \& Ugwu, S. I. (2011). The proximate and mineral compositions of five major rice varieties in Abakaliki, South-Eastern Nigeria. International Journal of Plant Physiology and Biochemistry 3(2), 25-27.

Otegbayo, B., Oguniyan, D., \& Akinwumi, O. (2013). Physicochemical and functional characterization of yam starch for potential industrial applications. Starch 65, 1-16.

Prasad, K., Singh, Y., \& Anil, A. (2012). Effects of grinding methods on the characteristics of Pusa 1121 rice flour. Journal of Tropical Agriculture and Food Science 40(2), 193-201.

Shafi, S., Wani, I. A., Gani, A., Sharma, P., Wani, H. M., Masoodi, F. A., \& Hamdani, A. M. (2016). Effect of water and ether extraction on functional and antioxidant properties of Indian horse chestnut (Aesculus indica Colebr) flour. Food Measurement and Characterization 10, 387-395.

Singh, N., Singh, J., Kuar, L., Sodhi, N. S., \& Gill., B. S. (2003). Morphology, thermal and rheological properties of starches from different botanical sources. Food Chemistry 81(2), 219-231.

Suwonsichon, T., Chueamchaitrakun, P., Chompreeda, P., Haruthaithanasan, V., \& Kasemsamran, S. (2011). Physical properties of butter cake made from mixed Hom-Mali and glutinous rice flours. Kasetsart Journal (Natural Science) 45, 295-304.
Tharise, N., Julianti, E., \& Nurminah, M. (2014). Evaluation of physico-chemical and functional properties of composite flour from cassava, rice, potato, soybean and xanthan gum as alternative of wheat flour. International Food Research Journal 21(4), 1641-1649.

Tong, L. T., Gao, X., Lin, L., Liu, Y., Zhong, K., Liu, L., Zhou, X., Wang, L., \& Zhou, S. (2015). Effects of semidry flour milling on the quality attributes of rice flour and rice noodles in China. Journal of Cereal Science 62, 45-49.

Wang, L., Guo, J., Wang, R. T., Shen, C., Li, Y., Luo, X., Li, Y., \& Chen, Z. (2016). Studies on quality of potato flour blends with rice flour for making extruded noodles. Cereal Chemistry 93(6), 593-598.

Yang, L., Zhang, H., Cheng, L., Gu, Z., Hua, D., Qi, X., Qian, H., \& Wang, L. (2014). Effect of extrusion on the hydrophilic antioxidant capacity of four whole grains. Journal of Food and Nutrition Research 2(2), 80-87.

Yani, A., Arief, R. W., \& Mulyanti, N. (2013). Processing of banana flour using a local banana as raw materials in Lampung. International Journal on Advanced Science Engineering Infomation Technology 3(4), 26-30.

Ye, L., Wang, C., Wang, S., Zhou, S., \& Liu, X. (2016). Thermal and rheological properties of brown flour from Indica rice. Journal of Cereal Science 70, 270-274. 